\title{
Dependency in Activities of Daily Living Following Limb Trauma in Elderly Referred to Shahid Beheshti Hospital, Kashan, Iran in 2013
}

\author{
Negin Masoudi Alavi ${ }^{1}$; Azade Safa ${ }^{2,}$; Masoumeh Abedzadeh-Kalahroudi ${ }^{3}$ \\ ${ }_{1}^{1}$ Trauma Nursing Research Center, Kashan University of Medical Sciences, Kashan, IR Iran \\ 2 Department of Medical Surgical Nursing, School of Nursing and Midwifery, Kashan, IR Iran \\ ${ }^{3}$ Trauma Research Center, Kashan University of Medical Sciences, Kashan, IR Iran \\ ${ }^{*}$ Corresponding author: Azade Safa, Department of Medical Surgical Nursing, School of Nursing and Midwifery, Kashan, IR Iran. Tel: +98-3615550021, Fax: +98-3615556633, E-mail:
} azade.fazel@yahoo.com

Received: May 24, 2014; Revised: July 12, 2014; Accepted: August 16, 2014

\begin{abstract}
Background: Activities of daily living (ADL) are an important indicator of health and independence in elderly. It provides useful information for proper planning in the field of elderly care. Trauma in elderly population is frequent and can negatively affect the independence in ADL.

Objectives: The purpose of the present study was to evaluate elderly independence in activities of daily living (ADL) following limb trauma and its related factors in patients referred to trauma emergency ward of Shahid Beheshti Hospital, Kashan, Iran, in 2013.

Patients and Methods: This descriptive study was conducted on 200 traumatic patients admitted to trauma emergency ward of Shahid Beheshti Hospital in 2013. The questionnaire used in this study had three parts as demographic data, information related to trauma and ISADL (independency scale of activities of daily living). ISADL was completed in emergency ward to declare pretraumatic status; it was also completed 1 and 3 months after trauma. Statistical analysis was conducted by Chi-square test, One-way and two-factor ANOVA, and Multiple regression analysis. Data analysis was conducted using SPSS software, version 16.

Results: The average age of participants was $70.57 \pm 9.05$ years. In total, $80.5 \%$ of the elderly were completely independent in ISADL before trauma; this decreased to $13.5 \%$ one month after trauma. Besides, $32 \%$ of the elderly were completely or relatively dependent three months after trauma. Two-factor ANOVA showed a significant association between the scores of ISADL, the time interval and the type and location of an injured organ, and having the surgery as a treatment.

Conclusions: More than three-quarters of the elderly were independent in ISADL before the trauma, but trauma in elderly patients had a substantial negative effect on patients' ability and ADL function.
\end{abstract}

Keywords: Activities of Daily Living; Limb; Trauma; Elderly

\section{Background}

In recent years, there has been an increase in geriatric population worldwide (1). According to the recent studies, elderly population of the United States has been growing rapidly since 1980 at a rate of $21 \%$. By the year 2040 , this percentage is estimated to reach nearly $20 \%$ of the total population in the US (2). This trend can be seen in many other countries including Iran. More than $7 \%$ of Iran population is elderly (3). The incidence of health problems increases in this age group, such as cognitive impairment, chronic diseases, and musculoskeletal disorders (1). The elderly consume $29 \%$ of medical care costs (4). The propensity for fall-related injury in elderly is due to a high prevalence of clinical diseases (e.g. osteoporosis, impaired vision, impaired balance) and age-related physiologic changes (e.g. slowed protective reflexes), which make even a mild fall particularly dangerous (5, 6). In a study performed in Iran, Adib Hajbaghery and Masoodi Alavi found that hip fractures due to osteoporosis occur 10 years sooner than developed countries showing a high risk of fractures in elderly in this country
(7). Trauma in the elderly population is frequent and associated with significant mortality and morbidity rates (2). Trauma is the fourth cause of death in the world (8). Chang et al. reported a mortality rate of nearly $10 \%$ in injured patients with a mean age of 77.5 years (2). Mohtasham Amiri et al. found that trauma was the second cause of hospitalization in elderly in hospitals of Rasht, Iran (9). Fractures due to fall and accidents are considered as important public health problems among elderly $(1,10)$. Compared to individuals without fractures, those with a previous hip fracture have a two to threefold higher risk of sustaining a subsequent fracture (11). Elderly patients have worse outcomes compared to the younger trauma patients (1). Approximately $5-20 \%$ of falls have serious consequences including major head trauma, major lacerations, or fracture and may lead to immobility or death (12). Elderly with hip fractures following falls have $20 \%$ to $30 \%$ mortality within one year of fracture (6). In a study in Shiraz, $24.6 \%$ of elderly remained disabled following trauma (13). Fall-related injuries are often associated with

Copyright ( ) 2014, Kashan University of Medical Sciences; Published by Kowsar. This is an open-access article distributed under the terms of the Creative Commons Attribution-NonCommercial 4.0 International License (http://creativecommons.org/licenses/by-nc/4.0/) which permits copy and redistribute the material just in noncommercial usages, provided the original work is properly cited. 
considerable long-term morbidity. Among communitydwelling fallers with hip fractures, between $25 \%$ and $75 \%$ do not recover their prefracture level of function in ambulation or activities of daily living (6). Fear of falling also has been recognized as a negative consequence of falls (14). Surveys have reported that between 30\% and $73 \%$ of older persons who had fallen acknowledge a fear of falling (8). Loss of confidence in the ability to ambulate safely can result in further functional decline (10), depression, feelings of helplessness, and social isolation (6, 14). Independence in activities of daily living (ADL) is an important indicator of health. It provides useful information for proper planning in the field of elderly care (15). ADLs are essential activities that a person needs to perform to be able to live independently. ADLs are defined as "the things we normally do such as feeding, bathing, dressing, grooming, working, homemaking" (16). In spite of common believes that elderly are accompanied by dependency, several studies showed that people can enjoy an independent life in elderly (4). Habibi et al. reported that only $0.7 \%$ of elderly were completely dependent, $5.9 \%$ were relatively dependent and $93.4 \%$ were completely independent (4). Tavakoli et al. also reported that more than $80 \%$ of people aged $65-74$ years, more than $70 \%$ of people aged 75-84 years, and a half of those older than 85 years were independent in performing activities of daily living (17). Trauma and injuries can negatively affect independence in ADL. Inaba et al. reported that most elderly (98\%) were living independently at home before injury. However, 3 years after injury, only $63 \%$ were living independently and $20 \%$ required home care (18). It seems that aging is not a factor for inevitable dependence of daily living activities, but trauma in the elderly can change this life process and lead to dependency. Gill et al. reported that $43.8 \%$ of elderly fallers had no recovery after one year (19). Sipila et al. also reported that only $40 \%$ of hip fracture survivors recovered to their prefracture ambulatory level and only $20 \%$ recovered to prefracture level in advanced mobility tasks (14). There are different and conflicting results about the rate of dependency following trauma in other countries $(14,18,19)$, while there is not enough information about this important issue in Iran. Geographic variation in trauma patterns may occur, but there is limited information available about geriatric trauma in Kashan. Estimation of ADL capabilities after trauma is essential for proper nursing care planning and family education. It also gives us information about the need for rehabilitation services.

\section{Objectives}

The aim of this study was to evaluate the independence of elderly in activities of daily livings (ADL) following limb trauma and its related factors in patients referred to trauma emergency ward of Shahid Beheshti Hospital, Kashan, Iran in 2013.

\section{Patients and Methods}

\subsection{Study Design}

This descriptive study was conducted in autumn and winter of 2013 in the trauma emergency ward of Shahid Beheshti Hospital in Kashan, Iran. It is the only general hospital in Kashan city and provides medical care for about 400000 populations, and all serious injuries in this area are referred to this hospital.

\subsection{Subjects}

Sampling population were elderly with limb trauma referring to emergency ward of Shahid Beheshti Hospital. Sample size was calculated based on the formula $(\mathrm{ZS} / \mathrm{E})^{2}$ with an alpha of 0.05 , sampling error of 2 and estimated standard deviation of ADL one month after limb trauma as 14 according to a pilot study performed previously on 20 patients. Therefore, 188 subjects were estimated to be needed; however, 200 subjects entered sequentially to the study to compensate possible attrition. The inclusion criteria were age over 60 years, no history of dementia, ability to respond to questionnaires, and independence in activities of daily living before injury. The exclusion criterion was refusal of subjects to continue the study.

\subsection{Measurement}

The questionnaire used in this study had three parts. The first part of the questionnaire included questions regarding demographic information (age, sex, education level, marital status, occupation, place of residence, and socioeconomic status). The second part included information related to trauma such as time of trauma (morning, noon and afternoon, and night), place of trauma (home or out of home), cause of trauma (fall or accident), type of trauma (fracture, contusion or dislocations), location of an injured organ (upper limb, pelvic, femur, knee and below knee) and history of previous diseases. Content validity of the first and second parts of the questionnaire was approved by 10 experts and their comments were applied. Reliability of the questionnaire was set at 0.95 by split-half method on 20 patients. The third part was ISADL (Independency Scale of Activities of Daily Living) used to evaluate independency in ADL one month before and one and three months after traumatic injury. This questionnaire was designed by Yaghmaei to assess independency in activities of daily living in elderly (15). ISADL has 20 questions about activities of daily living such as bathing, toileting, personal hygiene, shopping, managing finances, transporting, climbing stairs, walking, cleaning, dressing, using the telephone, washing and ironing clothes, preparing meal, eating and drinking, controlling urination and defecation, taking medications, getting up from a chair, going to bed and getting up from the bed, sorting and preparing the 
bed. Every item received the scores of 1-4 (1, completely dependent; 2 , relatively dependent; 3 , the relatively independent; 4 , completely independent in activities of daily living). The score range was 20-80. Elderly who got 60-80 of score were considered independent, 40-60 as relatively independent, 20-60 as relatively dependent and 20 as completely dependent. In the study of Yaghmaei, content validity of ISADL questionnaire was confirmed by 10 nursing instructors (15). Reliability of the questionnaire was set at 0.98 by Cronbach's Alpha. Independence status score was calculated for each patient, with a score of four indicating full ability in ADL in every item. The questionnaire was completed by interview in the emergency department to declare ADL one month before injury. The questionnaires were completed at least 6 hours after patients' admission to the emergency department and when patients were stable then the patients were followed and the questionnaires were completed at 1 and 3 months after trauma. The second author interviewed all patients who met the inclusion criteria in emergency department in morning and evening shifts. Telephone numbers and addresses of patients were recorded in the questionnaires. After 1 and 3 months, the patients were called by the second author and the questionnaires were completed through telephone interviews.

\subsection{Statistical Analysis}

Statistical analysis was conducted using SPSS software, version 16 (SPSS Inc., Chicago, Illinois). Normal distribution of data was tested by Kolmogorov-Simonov Test. The Chi-square test was used to assess dependency level before and after trauma. One-way ANOVA was used to assess the difference between ISADL scores in different time intervals. A two-way ANOVA found an association between time intervals and other variables in the ISADL score. Multiple regression analysis was used to show the variables that could made the model with ISADL scores as a dependent variable. The significance level was set at $\mathrm{P}<$ 0.05 in all testes.

\subsection{Ethical Consideration}

This study was approved by the research council of Faculty of Nursing and Midwifery and its ethical aspects were approved by the Research Ethics Committee of Kashan University of Medical Sciences, Kashan, Iran. Furthermore, necessary licenses were obtained from the authorities of the concerned hospital. The purposes of the study were explained to the participants and all signed a written informed consent and assured of the confidentiality of information.

\section{Results}

The average age of participant was $70.57 \pm 9.05$ years. In total, 119 (59.5\%) of the participants were female. Before the trauma, about one-thirds of the participants lived alone. Seventy patients (35\%) had injuries in pelvic; other areas of injury were 41 (20.5\%) in upper limb, 58 (29\%) in femur, and 31 (15.5\%) in knee and below knee. Patients' characteristics are presented in Table 1.

In total, $44 \%$ of elderly had a history of previous trauma. Among them $63.6 \%$ had fractures; $29.5 \%$ had soft tissue injuries and $6.9 \%$ had head trauma. Previous trauma happened $2.37 \pm 3.77$ years before the current trauma. Previous trauma was $69.3 \%$ in lower limb, $17 \%$ in upper limb and $13.7 \%$ in other organs. Most injuries were occurred in the morning hours (45.5\%), around $8 \mathrm{AM}$. In total, $75 \%$ of patients had undergone surgery in their treatment (internal fixator (65.5\%), skeletal traction (6\%), amputation and surgical reduction (3.5\%). Other treatments were splint and casting (6.5\%), rest and medical treatment (18.5\%). In total, $80.5 \%$ of the elderly were completely independent based on ISADL before trauma; this decreased to $13.5 \%$ one month after trauma. $32 \%$ of the elderly were completely or relatively dependent 3 months after trauma. There was a significant reduction in ISADL one month after trauma.

\begin{tabular}{|c|c|}
\hline Demographic Data of Elderly & Results \\
\hline \multicolumn{2}{|l|}{ Gender } \\
\hline Female & $119(59.5)$ \\
\hline Male & $81(40.5)$ \\
\hline \multicolumn{2}{|l|}{ Marital status } \\
\hline Married & $118(59)$ \\
\hline Widowed & $82(41)$ \\
\hline \multicolumn{2}{|l|}{ Education } \\
\hline Uneducated & $134(67)$ \\
\hline Below diploma & $54(27)$ \\
\hline Diploma and higher & $12(6)$ \\
\hline \multicolumn{2}{|l|}{ Occupation } \\
\hline Retired & $34(17)$ \\
\hline Housekeeper & $114(57)$ \\
\hline Farmer & $31(15.5)$ \\
\hline Other & $21(10.5)$ \\
\hline \multicolumn{2}{|l|}{ Socioeconomic status } \\
\hline Good & $29(14.5)$ \\
\hline Moderate & $112(56)$ \\
\hline Poor & $59(29.5)$ \\
\hline \multicolumn{2}{|l|}{ Place of trauma } \\
\hline Home & $105(52.5)$ \\
\hline Out of home & $95(47.5)$ \\
\hline \multicolumn{2}{|l|}{ Cause of trauma } \\
\hline Fall & $148(74)$ \\
\hline Accident & $52(26)$ \\
\hline \multicolumn{2}{|l|}{ Type of trauma } \\
\hline Fracture & $161(80.5)$ \\
\hline Contusion or dislocations & $39(19.5)$ \\
\hline
\end{tabular}


Masoudi Alavi N et al.

\begin{tabular}{|c|c|c|c|c|c|c|}
\hline \multirow{2}{*}{$\begin{array}{l}\text { Level of Independence in ADL } \\
\text { Completely dependent }\end{array}$} & \multirow{2}{*}{$\frac{\text { Before Trauma }}{0(0)}$} & \multicolumn{2}{|l|}{ One Month After Trauma } & \multicolumn{2}{|c|}{ Three Months After Trauma } & \multirow[t]{2}{*}{ PValue } \\
\hline & & $7(3.5)$ & & \multicolumn{2}{|c|}{$11(5.5)$} & \\
\hline Relatively dependent & $5(2.5)$ & $116(58)$ & \multicolumn{3}{|c|}{$53(26.5)$} & \\
\hline Relatively independent & $34(17)$ & $50(25)$ & \multicolumn{3}{|c|}{$91(45.5)$} & \\
\hline Completely Independent & $161(80.5)$ & $27(13.5)$ & \multicolumn{3}{|c|}{$45(22.5)$} & \\
\hline Results & $70.22 \pm 12.35$ & $41.25 \pm 13.44$ & \multicolumn{3}{|c|}{$48.81 \pm 17.66$} & 0.0001 \\
\hline \multicolumn{7}{|c|}{$\begin{array}{l}\text { a Abbreviation: ADL, activities of daily living. } \\
\text { b }{ }_{\text {Data are presented as No. }(\%) \text { or Mean } \pm \text { SD. }}\end{array}$} \\
\hline \multicolumn{7}{|c|}{ Table 3. Two-Way ANOVA Results for Activities of Daily Living Score, Before, One and Three Months After Trauma and Other Variables } \\
\hline \multirow[t]{2}{*}{ Two-Way ANOVA } & & \multicolumn{5}{|c|}{ Source of Variation } \\
\hline & & SS & DF & MS & $\mathbf{F}$ & PValue \\
\hline \multicolumn{7}{|c|}{ Type of trauma (fracture, dislocation, contusion) } \\
\hline Interaction & & 3460.9 & 4 & 865.2 & 4.339 & 0.002 \\
\hline Type of trauma & & 7102.5 & 2 & 3551.2 & 17.8 & 0.0001 \\
\hline Before, 1 and 3 months after tra & ma & 18195.2 & 2 & 9097.6 & 45.6 & 0.0001 \\
\hline Residual & & 117861 & 591 & 199.426 & & \\
\hline \multicolumn{7}{|c|}{$\begin{array}{l}\text { The location of injured organ (upper limb, knee and } \\
\text { below knee, pelvic, femur) }\end{array}$} \\
\hline Interaction & & 8530.2 & 18 & 473.9 & 3.12 & 0.0001 \\
\hline Location of injured organ & & 33390.7 & 9 & 3708.9 & 24.43 & 0.0001 \\
\hline Before, 1 and 3 months after tra & ma & 30876.8 & 2 & 15438.4 & 101.7 & 0.0001 \\
\hline Residuals & & 86513.5 & 570 & 151.7 & & \\
\hline \multicolumn{7}{|l|}{ Having a surgery } \\
\hline Interaction & & 6268.5 & 2 & 2134.3 & 18.22 & 0.0001 \\
\hline Having a surgery & & 20013.3 & 1 & 20013.3 & 116.4 & 0.0001 \\
\hline Before, 1 and 3 months after tra & ma & 51195.4 & 2 & 25597.7 & 148.8 & 0.0001 \\
\hline Residuals & & 102142.6 & 594 & 171.9 & & \\
\hline
\end{tabular}

a Abbreviations: ANOVA, analysis of variance; SS, sum of square, DF, degree of freedom, MS, mean of square; F, F-test.

Table 4. Multiple Regression Analyses of Associations Between Variables With Elderly Independence Before, One and Three Months After Trauma ${ }^{\text {a }}$

\begin{tabular}{|c|c|c|c|c|c|}
\hline & P Value & T & Beta & Adjusted $\mathbf{R}^{2}$ & $\mathbf{R}^{2}$ \\
\hline Level of independence in ADL before trauma & & & & 0.451 & 0.671 \\
\hline Age & 0.0001 & -5.426 & -0.395 & & \\
\hline Marital status & 0.036 & 2.108 & 0.148 & & \\
\hline Level of independence in ADL 1 month after trauma & & & & 0.527 & 0.726 \\
\hline Gender & 0.024 & 2.284 & 0.169 & & \\
\hline Age & 0.001 & -3.443 & -0.233 & & \\
\hline Occupation & 0.043 & -2.034 & -0.136 & & \\
\hline Education & 0.001 & 3.487 & 0.246 & & \\
\hline Cause of trauma & 0.021 & 2.330 & 0.165 & & \\
\hline Location of injured organ & 0.024 & -0.130 & -2.276 & & \\
\hline Having a surgery & 0.0001 & 0.297 & 4.180 & & \\
\hline Level of independence in ADL 3 months after trauma & & & & 0.475 & 0.691 \\
\hline Age & 0.0001 & -4.881 & -0.347 & & \\
\hline Having a surgery & 0.0001 & 5.246 & 0.392 & & \\
\hline Kind of treatment & 0.017 & 2.415 & 0.149 & & \\
\hline
\end{tabular}

a Abbreviation: ADL, activities of daily living. 
The ISADL score improved three months after trauma, but it did not reach to its preinjury period (Table 2). Twoway ANOVA showed a significant association between the scores of ISADL, time interval and type and location of an injured organ, and the undergoing surgery as a treatment (Table 3). Other variables including gender, education, and marital status had no significant effect.

In multiple regression analyses, age and marital status could explain $67.1 \%$ of independence in ISADL before trauma. One month after trauma, gender, age, occupation, education, cause of trauma, location of an injured organ and having surgery for treatment made a model with independence in ISADL. All these variables could explain $72.6 \%$ of ISADL score. Three months after injury only age, having surgery and kind of treatment showed significant associations with ISADL and could explain $69.1 \%$ of this variable (Table 4).

\section{Discussion}

The present study showed that $80.5 \%$ of elderly population were independent before trauma; this reached to $13.5 \%$ and $22.5 \%, 1$ and 3 months after trauma. The lowest score of ISADL was reported one month after trauma. Inaba et al. reported that most elderly (98\%) were living independently at home before injury. However, at longterm follow-up (a mean of 2.8 years), only $63 \%$ were living independently and 20\% still required homecare (18). Besides, Gill et al. reported that $43.8 \%$ of elderly fallers had no recovery after one year (19). Sipila et al. reported that only $40 \%$ of hip fracture survivors recovered to their prefracture ambulatory level and only $20 \%$ recovered to their prefracture level in advanced mobility tasks 6 weeks after discharge (14). Kelley-Quon et al. also reported that ADL scores declined after 12 months of trauma (20). These findings were probably due to the fact that the elderly were at rest until a month after trauma, but three months after trauma were launched by using aids and had begun rehabilitation. These findings suggest that prevention and treatment of trauma should be a high priority when decisions are made to allocate resources aimed to reduce the burden of disability in older persons. More than a half of participants were women. This finding is consistent with the results of Buczak-Stec et al. in Poland reporting that hospitalization ratio due to falls was much higher for women than men (21). Fracture occurs probably in reduced bone mass and impaired bone geometry in older women (11). Multiple regression analysis showed that gender had an association with ISADL one month after trauma and women showed a better improvement in their ISADL. The reason might be that women receive more support after trauma. Many studies showed that perceived support has a direct effect on health and wellbeing of older adults (22). Gill et al. reported more disability in women after trauma (23). Moreover, Gonzalez et al. reported that women with wrist fractures exhibited greater decrease of QOL (Quality of Life) than men 6 months after fall (24). This is not consistent with the findings of the current study. The present study showed that risk of dependency due to a trauma increases with age consistent with previous studies $(6,21)$. The present study showed that most frequent geriatric trauma injuries occur due to falls. According to Gill, about one of three people older than 65 years falls annually; this rate increases with advanced age (19). A serious fall injury is often a defining event in the life of an older person, and can dramatically affect the function of elderlies (19). Fazel et al. reported fall as the most common cause of home-related injury in Kashan, Iran in one-fifth of elderlies (25). Falling could be simply a marker for the progression of "normal" age-related changes in vision, gait and strength. For instance, visual impairment increases the risk of falling for about 2.5 times (6). According to Brand et al. $49 \%$ of patients with rheumatic disease reported one or more falls in previous 12 months (26). In the present study, most injuries were occurred in the morning hours around 8 AM, which could be due to a sudden rise from bed or side effects of drugs. The elderly should be instructed to get up from the bed slowly in the mornings, and sit on the edge of the bed for about a minute. In total, $60 \%$ of participants had a history of previous trauma. Individuals who had fallen have a threefold increased risk of falling again. Recurrent falls in an individual are frequently due to the same previous causes (6).

In the present study, fractures (80.5\%) were the main consequences of trauma. Fractures are the most serious consequence of falls for seniors (27). The most common injured regions were pelvic (35\%), femur (29\%), upper limb (20.5\%) and knee and below knee (15.5\%). Community-dwelling older persons who survive a fracture need special attention (14). In addition, Gill et al. reported that $47.7 \%$ of participants had hip fractures and post-fall functional trajectories were consistently worse after a hip fracture than other injuries (28). Hip fracture is the second major cause of bedridden (26). Studies showed that patients with hip fracture have poor recovery in their deficiency in mobility might be permanent (14). In the present study, more than three-quarters of the elderly were independent based on ISADL before trauma, but trauma in elderly patients had a substantial negative effect on their ability and ADL function. In summary, our group is the first to follow a longitudinal group of elderly adults after trauma in Kashan, Iran and identify a significant and progressive loss of functional ability. Clinical consequences include increased risk of future decline, loss of independence, and mortality. We propose that care of geriatric patients with trauma should move beyond prevention of death and include multidisciplinary care targeted rehabilitation and prevention of permanent functional impairment. The elderly patients following trauma should be cared for by specialist nurses. Telephone counseling could be helpful. This study had some limitations; first, the ISADL questionnaires were completed by phone call one and three months after trauma, which might affect 
the responses. The second limitation of this study was relying on self-report information, which could cause bias. We just followed patients for three months. It seems that we need longer follow-up periods to have a better image of ISADL following trauma. We recommend to continue patients' follow-up for longer periods. We also recommend interventional studies to improve ISADL following trauma in elderly.

\section{Acknowledgements}

This article is derived from a master's thesis in nursing. The authors would like to gratitude all patients who participated in this study, without their participation, this study would not have been possible.

\section{Authors' Contributions}

Negin Masoudi Alavi was responsible for the study concept and design, made critical revisions to the paper, participated in data analysis and supervised the study; Azade Safa participated in study concept, performed data collection and literature search and prepared the first draft of the manuscript and Masoumeh Abedzadeh revised the study draft.

\section{Funding/Support}

This study was supported by the Deputy of Research, Kashan University of Medical Sciences, Kashan, Iran (Grant no: 92133).

\section{References}

1. Kara H, Bayir A, Ak A, Akinci M, Tufekci N, Degirmenci S, et al. Trauma in elderly patients evaluated in a hospital emergency department in Konya, Turkey: a retrospective study. Clin Interv Aging. 2014;9:17-21.

2. Chang W, Tsai S, Su Y, Huang C, Chang K, Tsai C. Trauma mortality factors in the elderly population. Int J Gerontol. 2008;2(1):11-7.

3. Adib Hajbaghery M, Rajaei M. [Lived experiences of elderly home residents: a qualitative study]. Behbood J. 2011;15(5):372-83.

4. Habibi A, Nikpour S, Seiedoshohadaei M, Haghani H. [Quality of Life and Status of Physical Functioning among Elderly People in West Region of Tehran: A Cross-Sectional Survey]. Iran J Nurs. 2008;21(53):29-39.

5. Oliveira KA, Rodrigues CC, Helu Mendonca Ribeiro RC, Martins CS, Abelan US, Fernandes AB. Causes of trauma in elderly patients treated in emergency unit. J Nurs UFPE Line . 2013;7(4):1113-9.

6. Rubenstein LZ, Josephson KR. Falls and their prevention in elderly people: what does the evidence show? Med Clin North Am. 2006;90(5):807-24.

7. Adib Hajbaghery M, Masoodi Alavi N. Characteristic of patients with osteoporotic hip fracture in Kashan, Iran. Webmed Cent 2011;2(10).

8. Zohoor A, Asadi F. [Suggested a National Trauma Registry System for Iran]. J Res Health Sci. 2004;4(1):64-70.

9. Mohtasham Amiri Z, Toloei M, Farazmand A. [Causes of Patients' Hospitalization in Guilan University Hospitals].J Guilan Univ Med Sci. 2005;11(42):28-32.

10. Kannus P, Sievanen H, Palvanen M, Jarvinen T, Parkkari J. Prevention of falls and consequent injuries in elderly people. Lancet 2005;366(9500):1885-93.

11. Mikkola T, Sipila S, Portegijs E, Kallinen M, Alen M, Kiviranta I, et al. Impaired geometric properties of tibia in older women with hip fracture history. Osteoporos Int. 2007;18(8):1083-90.

12. van Diest M, Lamoth CJ, Stegenga J, Verkerke GJ, Postema K. Exergaming for balance training of elderly: state of the art and future developments. J Neuroeng Rehabil. 2013;10:101.

13. Nader F, Rakeei S. [The epidemiologic aspects of trauma in the elderly in Shiraz hospital 1383]. J Jahrom Univ Med Sci. 2007; 4(4):41-6.

14. Sipila S, Salpakoski A, Edgren J, Heinonen A, Kauppinen MA Arkela-Kautiainen $\mathrm{M}$, et al. Promoting mobility after hip fracture (ProMo): study protocol and selected baseline results of a yearlong randomized controlled trial among community-dwelling older people. BMC Musculoskelet Disord. 2011;12:277.

15. Yaghmaei F. [Introducing a new scale for activities of daily living]. J Nurs Midwifery Shahid Beheshti Univ Med Sci.;15(50):12-30.

16. Barry LC, Murphy TE, Gill TM. Depression and functional recovery after a disabling hospitalization in older persons. J Am Geriatr Soc. 2011;59(7):1320-5.

17. Tavakoli H, Ahmadi Amoli H, Yaghoubi Notash A, Adelyazdankhah Konari A, Gholkhani F, Khashayar P. [Trauma-related morbidity and mortality in elderly patients. Iranian Journal of Ageing]. Iran J Ageing. 2009;4(11):30-6.

18. Inaba K, Goecke M, Sharkey P, Brenneman F. Long-term outcomes after injury in the elderly. JTrauma. 2003;54(3):486-91.

19. Gill TM, Murphy TE, Gahbauer EA, Allore HG. The course of disability before and after a serious fall injury. JAMA Intern Med. 2013;173(19):1780-6.

20. Kelley-Quon L, Min L, Morley E, Hiatt JR, Cryer H, Tillou A. Functional status after injury: a longitudinal study of geriatric trauma. Am Surg. 2010;76(10):1055-8.

21. Buczak-Stec E, Gorynski P. Fall related hospital admissions among seniors in Poland in 2010. Przegl Epidemiol. 2013; 67(1):57-62.

22. Chalise HN, Kai I, Saito T. Social support and its correlation with loneliness: a cross-cultural study of Nepalese older adults. Int J Aging Hum Dev. 2010;71(2):115-38.

23. Gill TM, Allore HG, Gahbauer EA, Murphy TE. Change in disability after hospitalization or restricted activity in older persons. JAMA 2010;304(17):1919-28.

24. Gonzalez N, Aguirre U, Orive M, Zabala J, Garcia-Gutierrez S, Las Hayas C, et al. Health-related quality of life and functionality in elderly men and women before and after a fall-related wrist fracture. Int J Clin Pract. 2014;68(7):919-28.

25. Fazel MR, Fakharian E, Razi E, Abedzadeh-Kalahroudi M, Mahdian M, Mohammadzadeh M, et al. Epidemiology of home-related injuries during a six-year period in kashan, iran. Arch Trauma Res. 2012;1(3):118-22.

26. Brand C, Aw J, Lowe A, Morton C. Prevalence, outcome and risk for falling in 155 ambulatory patients with rheumatic disease. APLAR J Rheumatol. 2005;8(2):99-105.

27. Inokuchi K. [Accidental falls]. Nihon Rinsho. 2013;71(6):1042-6.

28. Gill TM, Murphy TE, Gahbauer EA, Allore HG. Association of injurious falls with disability outcomes and nursing home admissions in community-living older persons. Am J Epidemiol. 2013;178(3):418-25. 